\title{
A CASE STUDY ON THE LANGUAGE AND SOCIO-CULTURAL \\ CHALLENGES EXPERIENCED BY INTERNATIONAL STUDENTS \\ STUDYING AT CAPE PENINSULA UNIVERSITY OF TECHNOLOGY
}

\author{
M. K. Ralarala \\ The Language Centre \\ University of Fort Hare \\ Alice, South Africa \\ E-mail: MRalarala@ufh.ac.za
}

\section{E. A. Pineteh}

Unit for Academic Literacy

Faculty of Humanities

University of Pretoria

E-mail: pineteh.angu@up.ac.za

\section{Z. Mchiza}

Population Health, Health Systems and Innovation Unit

Human Sciences Research Council

Cape Town, South Africa

E-mail: zmchiza@hsrc.ac.za

\section{ABSTRACT}

South African universities have become institutions of choice for international students, particularly those who hail from other African countries. Apart from presenting a beehive of cultures and languages, this segment of the student population makes an immense contribution in terms of research, teaching and learning. In spite of international students' contributions to scholarship and development at Cape Peninsula University of Technology, their pursuit of academic success is often impeded by an array of challenges which includes Limited English Proficiency (LEP), Limited Language Support (LLS) and Limited Access to Facilities (LAF), all of which may prevent them from gaining access to the academic discourse of their chosen discipline of study. Adopting a mixed methods approach, this study examines international students' experiences in relation to both language and socio-cultural challenges. Findings reveal that, for international students to adapt academically and socially and be in a position to fulfil the requirements of their respective academic programmes, CPUT should provide a socially inclusive teaching and learning environment. In addition, the university should provide adequate and accessible English language support programmes/projects.

Key words: access, Cape Peninsula University of Technology, international students, language challenges, socio-cultural challenges, success in higher education 


\section{INTRODUCTION}

In recent years, Cape Peninsula University of Technology (CPUT) has become a pole of attraction for international students. In an earlier study by Pineteh and Ralarala (2013), it was pointed out that the number of registered international students in all faculties of the university was 3026 during the 2013 academic year. The enrolment for the 2014 academic year (see Table 1 for a detailed account) totalled 2940 (CPUT Management Information System (MIS) Statistics), Of these international students, the majority come from Francophone countries African students, particularly from Francophone countries, notably account for a significant number of the international students who participated in the present study. Although institutions of higher learning in South Africa embrace the notion of internationalisation, as evidenced by, among others, a significant proportion of the total number of enrolments being those of international students (Bartram 2008; Sheridan 2011), related literature suggests that most institutions (locally and internationally) are underprepared to provide a holistic educational experience for these international students. In the context of CPUT, the problem is particularly acute for three reasons: a) A significant number of international students that enrol in both undergraduate and post-graduate programmes have English as a Second Language (L2), and, in some cases, as a Third Language (L3); b) CPUT is recognised as an English-speaking university, and this is apparent in all its academic offerings; and c) The university does not have an established policy or system that enforces the screening of international students in order to determine their English language proficiency prior to admission (i.e., it lacks an International English Language Testing System - IELTS). Although this brief introduction might be considered too brief to give credit to other critical issues related to the issue of institutions being underprepared for international students, it also provides a glimpse into the complexity of the situation.

Table 1: Statistical information of International students' enrolment: (CPUT MIS 2014)

\begin{tabular}{|l|l|l|l|}
\hline \multirow{2}{*}{ Faculties } & \multicolumn{2}{|c|}{2014} \\
\cline { 2 - 4 } & Postgraduate & Undergraduate & Total \\
\hline Applied Sciences & 64 & 236 & 300 \\
\hline Business & 122 & 684 & 806 \\
\hline Education \& Social Sciences & 29 & 18 & 47 \\
\hline Engineering & 131 & 1204 & 1335 \\
\hline Health \& Wellness Sciences & 27 & 111 & 138 \\
\hline Informatics \& Design & 74 & 240 & 314 \\
\hline Grand Total & $\mathbf{4 4 7}$ & $\mathbf{2 4 9 3}$ & $\mathbf{2 9 4 0}$ \\
\hline
\end{tabular}

The number of international students in Table 1 is approximately 9 per cent of the total 
This study considers the language challenges of international students enrolled at CPUT and the lack of adequate English language support to meet their needs. These needs - if appropriately addressed - could presumably enable international students' access to the academic discourse, and thereby result in higher success rates among these students. Furthermore, the study explores the socio-cultural challenges experienced by these students in relation to their limited English language proficiency, and the manner in which these challenges affect them in a learning context that is foreign to them. To this end, this article argues that access and success are inextricably linked. For example, the academic performance of CPUT's international students depends, on the one hand, on their ability to culturally integrate in a new environment; and on the other hand, on the provision of adequate language support resources by the university (as well as easy access to those resources). Therefore, in examining and explicating both the language and socio-cultural challenges that tend to affect international students' learning, along with the notions of access and success in their academic endeavours, we draw on Cummins’s (1991; 2008; 2009) BICS/CALP theoretical framework, as well as on Hall and Hall’s (1990) Communication Model.

\section{RESEARCH OBJECTIVES}

- $\quad$ To investigate the English language and socio-cultural challenges faced by international students studying at CPUT;

- To assess the different facets and complexities of the international students's socio-cultural and language-related challenges;

- To critically examine how English language and socio-cultural challenges impact on international students' academic access and success; and

- $\quad$ To utilise the findings to provide recommendations to the university management.

\section{LITERATURE REVIEW}

The growing body of knowledge on the institutionalisation of higher education globally speaks explicitly to the upsurge of international students in modern universities (Bartram 2008; Kim 2011; Lee and Rice 2007). This body of knowledge explicitly outlines the contributions of international student communities to the generalised teaching and learning experiences in host institutions. It argues that they 'increase the diversity of student populations, add new perspectives to classroom conversations and ... increase our awareness and appreciation for other countries and cultures' (Lee and Rice 2007, 381). Although international students add a 
unique flair to university environments, they experience several challenges associated with cross-border human mobility, such as encountering strange languages, the need for cultural adaptation, feelings of isolation, homesickness, prejudices and so on (Bartram 2008; Swami et al. 2010). Interestingly, instead of fraternising and paying attention to the needs and challenges of foreign students, staff and students of host universities tend to alienate them (Kim 2011; Lee and Rice 2007). In the South African context, the often-neglected language difficulties of international students tend to play a significant role in their higher education experience. For example, self-perceived language proficiency is a key factor in both the socio-cultural and academic adjustment of international students in this context (Barratt and Huba 1994, 429; Yeh and Inose 2003, 23). To this end, this community of students opines that socio-cultural and academic needs are the two most important areas where they would like support (Bartram 2008, 666).

Similarly, studies such as those of Lee and Rice (2007) and Ramburuth and McCormick (2001), point to the relationship between language and socio-cultural challenges of international students. For example, Lee and Rice (2007), in their study of international students’ perceptions of discrimination, argue that challenges associated with language and cultural adaptation increase the psychological and sociocultural distress of international students. These challenges have strong implications for the quality of their social lives and academic performance (Swami et al. 2010, 57). The aforementioned authors contend that the role of English language abilities in the international student experience in higher education extends far beyond the academic context. For them, international students' English language aptitude influences their ability to insulate against perceived discrimination, and/or negotiate social relations with local students. In addition, those who speak English more frequently, at a higher level of fluency, or at a higher comfort level, are likely to experience lower levels of acculturative distress, such as isolation and lack of self-esteem (Karuppan and Barari 2011, 78; Swami et al. 2010; Yeh and Inose 2003, 23). Students with lower English proficiency are less able to insulate against perceived discrimination, so they are more likely to experience nostalgia (Poyrazli and Kavanaugh 2006, 275). Moreover, self-esteem is positively correlated with self-perceived language skills (Barratt and Huba 1994, 432). Lower English proficiency negatively impacts on the socio-cultural experience of international students. In many instances, even when students feel that their written language skills have been adequately addressed, they would still like additional formalised social interactions with host country students in order to acquire verbal language skills in a more informal setting (Sherry, Thomas, and Chui 2010, 37).

Generally, the overall cost of living and studying abroad is usually hefty for many 
international students. As they are either self-sponsored or funded by their governments, academic success is usually their primary objective. However, this objective is not easily attainable because they often struggle to negotiate 'basic academic procedures and living arrangements' owing to their language difficulties (Lee and Rice 2007, 386). In a qualitative study on African female scientists, Beoku-Betts (2004), illuminates white professors' prejudices against these women because of their accent. The same study confirms that language proficiency does not only affect the socio-cultural needs of international students, but also their academic performance. The self-perceived lack of English language abilities prevents students from interacting with classmates and even, at times, attending class. This could be because it also affects their choice of coursework and the quality of assessments. Students with low proficiency feel isolated and intimidated in the classroom (Kim 2011; Lee and Rice 2007; Ryan and Viete 2009). Perceived discrimination negatively affects learning outcomes, but English language skills can insulate students from this discrimination, allowing them to interact with other students, both inside and outside the classroom. Ultimately, some international students choose classes that require lower English language proficiency in order to circumvent their language difficulties (Constantine et al. 2005, 168). In the English classroom, language proficiency and confidence play a role in students' academic performance. For Kim (2011), there are several language-related challenges experienced by international students, such as difficulties with critical thinking, struggles to follow lectures because of their presentation, the importance of listening comprehension in those lectures, and the way in which the lecturer speaks.

Studies on international student experiences explore the discourse of students as 'customers' and 'consumers', and how these metaphors influence the recruitment of international students (Lee and Rice 2007; Swami et al. 2010). This implies that international students contribute immensely to the scholarship of research, teaching and learning, both in terms of revenues and skills. However, institutions do not accompany high numbers of international student recruitment 'with a strong consideration of their experiences after enrolment ...' (Lee and Rice 2007, 383). To this end, they advocate 'a critical necessity of institutions to identify ways of meeting the special needs of international students' (Lee and Rice 2007, 386). As the consequences of limited English language proficiency span many aspects of the international students' lives, institutional support plays a key role in international student success (Sheridan 2011, 138). These studies argue that host institutions can provide both academic and social language support, as well as means for cultural exchange. They can support students by working with faculty, adjusting the curriculum, and helping international 
students adjust to a new learning environment (Guo and Chase 2011, 316). Additionally, institutions can provide opportunities for international students to develop social relationships with English-speaking students to improve their language abilities, communication confidence, and increase opportunities for cultural exchange to help these students integrate into their new context (Sherry, Thomas, and Chui 2010, 44). Moreover, because international students face several challenges and internationalisation continues to develop in higher education, institutions are duty bound to take measures to address these challenges. This will potentially create an enabling environment, and thus make the community more welcoming for international students. This article also, therefore, outlines a variety of ways in which CPUT can provide both language and socio-cultural support for international students (McLellan 2009).

It is worth noting that this article is based on a study of one university and therefore the findings and recommendations are not generalizable, especially since the challenges of international students might differ from one university to another. However, the implications for local South African students cannot be completely ignored because, as revealed in the findings and conclusions, many local students also face similar language challenges.

\section{THEORETICAL FRAMEWORK}

To make meaning from the language and socio-cultural challenges of CPUT's international students, this study draws on Cummin's' theoretical model of basic interpersonal communicative skills (BICS) and cognitive academic language proficiency (CALP) (Cummins 1991; 2008; 2009). Although Cummin's model of language acquisition may be considered fundamental in explicating learners' language issues, in the present study it stands to reason that the scope of this study - which also entails socio-cultural issues, as drawn from the data demands further conceptualisation. Therefore, in order to fully comprehend the extent to which international students deal with socio-cultural issues within the context of CPUT, Hall and Hall's (1990) Communication Model is also relevant to this work, and thus it is employed as an additional theoretical lens for this study.

\section{Basic interpersonal communicative skills (BICS)}

BICS refers to social conversational fluency in a language (Cummins 2008, 71). This is the type of language proficiency that is acquired in order to address basic communication issues. For instance, responding and participating in a simple conversation in English about someone's well-being, impressions about the weather, and other similar topics could constitute classic 
examples of BICS.

\section{Cognitive Academic Language Proficiency (CALP)}

CALP relates to sophisticated and, possibly, abstract language proficiency - framed as the student's ability to understand and express, in both oral and written modes, concepts and ideas that are relevant to academic success (Cummins 2008). CALP refers to 'the extent to which an individual has access to and command of the oral and written academic registers of schooling' (ibid., 72). In relation to this notion, Cummins $(1991,75)$ further points out that '... academic aspects of L2 proficiency take considerably longer to develop to native-speaker norms than do conversational aspects', and, more importantly, ‘... transfer of academic skills occurs from minority students' L1 to English L2 such that instruction through the medium of L1 will result in no academic retardation in English. Notably, Cummins's theoretical conception is relevant to this study in the following ways: firstly, the segment of the student population under investigation is largely L2 and (in some cases) L3 speakers of English; and, secondly, the institution at which they are enrolled has English as its medium of instruction in all its programmes. We will elaborate on these issues later in the discussion as we deal with, among other things, the extent to which English language proficiency relates to an institution's academic discourse.

\section{Importance of the distinction between BICS and CALP}

Cummins $(2008,72)$ underscores the need to make a distinction between these two levels of proficiency. Accordingly, cognitive academic language proficiency is said to develop as a result of social interaction from as early as birth, and differentiation from BICS takes place subsequent to the early stages of schooling. Thus CALP ' ... reflect(s) primarily the language that children [and learners] acquire in school [and at university] and which they need to use effectively if they are to progress successfully ...'. A critical point being made, according to Cummins (2008, 72), is that educators and policy makers tend to conflate these levels of proficiency and this conflation tends to contribute significantly to academic difficulties for students who are learning English as an additional language, or who are studying through the medium of English, as in the case in the context of the current study. Furthermore, the conflation also carries the potential to contribute directly to the inappropriate placement of 'bilingual' students in a special academic programme (2008, 72). Arguably, this is academically dangerous, and thus carries the potential to misconstrue the type and the level of language support (English, in this case) that may be needed in an academic environment for LEP students. Therefore, the importance 
of distinguishing the conversational language proficiency from the academic aspects of second language performance cannot be overemphasised, especially when taking into account the duration of a lengthy period of time required for learners to attain the academic norms of English (Cummins 2008).

Another critical proposition posed by Cummins (1991, 2008), central to the CALP/BICS distinction, is the notion of overlapping continua along which an array of cognitive demands and contextual support emanate during specific language tasks or activities. Elaborating on the contextual dimension, Cummins $(2008,74)$ points out the following:

Context is constituted both by what we bring to a task (e.g., our prior knowledge, interests, and motivation) and the range of support that may be incorporated in the task itself (e.g., visual supports such as graphic organisers).

In respect of the first continuum, contextual support, a distinction between context-embedded and context-reduced communicative situations is outlined. In this regard, the former communicative situations, on the one hand, 'offer contextual clues to assist in the understanding of language, such as facial expression, gestures, and feedback ...' (Abriam-Yago, Yoder and Kataoka-Yahiro 1999, 145), and these communicative situations tend to take place in informal settings. The latter communicative situations, on the other hand, are linguistically demanding and entail lectures and learning materials or textbooks, and thus offer few clues $(1999,145)$. In terms of the second continuum, cognitive demands, some differentiation is made between cognitively undemanding and cognitively demanding communicative situations. In this instance, the former relates to 'subconscious activities' (Abriam-Yago, Yoder, and KataokaYahiro 1999, 145) that are common in everyday life. Conversely, the latter communicative situations demand a high level of conscious focus in order for the student to have a substantial grasp of concepts and language (Cummins 1991, 2008).

Notably, Cummins's theoretical framework has been applied in various studies which have dealt with, amongst others, the interface of language and content (see Rabatsoa and Singh 2012), as well as in studies where English Second Languages (ESL) school and university students are confronted with language difficulties that affect their academic achievement (see Abriam-Yago, Yoder, and Kataoka-Yahiro 1999; Kim 2011). It goes without saying therefore that, apart from being a utility that underpins our views, the framework carries potential to account for and provide guidance in terms of the analysis and interpretation of research findings in this study.

\section{Communication model}


Hall and Hall $(1990,3)$ present a convincing conceptualisation with particular reference to high and low context cultures and the manner in which this model relates to the understanding of communication complexities. They point out that 'any culture is primarily a system for creating, sending, storing, and processing information', and accordingly, 'Communication underlies everything' (1990, 3). Language is therefore the central 'tunnel' through which communication is realised. It can be argued that the three components, that is, language, culture and communication, are inextricably bound, and it may be rather impossible to disentangle them. Hall and Hall $(1990,7)$ contend that, 'the elements that combine to produce a given meaning events and context - are in different proportions ...' and this reality hinges on the notion of culture (Hall and Hall 1990). The former cultural dimension (high context culture) is defined as a situation in which less information is contained in the verbal part of a message and more in the context in which the message is delivered. Thus language, as a form of maintaining social harmony, is valued, and the use of ambiguity or indirectness and silence is also embraced (Adler and Rodman 2006). Examples of such cultures, according to Hall and Hall (1990), include Japanese, Arab and Mediterranean people. Arguably, the mere fact that African people subscribe to, or have the notion of, Ubuntu - the spirit of togetherness - embedded in their cultural idiosyncrasies, would lead one to categorise them in the domain of a high context culture. An important observation in relation to high and low context cultures made by AbriamYago, Yonder, and Kataoka-Yahiro $(1999,144)$ is the following:

Words chosen for communication may have numerous possible interpretations; meaning is derived from matching words with nonverbal cues and the specific situation. Cultures that emphasise intergenerational relationships and shared language styles create a cultural context that encourages bonds to develop among members of the culture.

On the contrary, the latter cultural dimension (low context culture) implies the carrying of explicit messages through words that contain most of the information, and as such, there is less focus on the situational context. In this domain, self-expression is valued, and feelings, desires and opinions are explicitly uttered. The Americans, Germans and the Swiss - to a certain degree - resonate with this cultural dimension (Adler and Rodman 2006). That much said, global integration, and cultural and linguistic contact has since - in many ways - influenced the overlap between these verbal communication styles across cultures.

The fundamental point being made is that cross-cultural communication is very profound and complex and, in order for its system to work and succeed, it 'requires attention to everything people do to survive, advance in the world, gain satisfaction from life' (Hall and Hall 1990, 4). In circumstances where it fails to succeed, its failure may be attributed to, among other 
elements, these: i) unconscious application of ‘one’s own rules to another system'; ii) deliberate rejection of rules - written or unwritten - and 'trying to force one's own rules on another system’ $(1990,4)$, as it shall be related to our discussion.

\section{RESEARCH DESIGN AND METHODOLOGY}

This study adopted a mixed methods approach (i.e., quantitative and qualitative methods) to uncover and analyse the intricacies of English language and socio-cultural challenges experienced by international students at CPUT. Given the objectives and choice of research methodology, a triangulation mixed method design was selected. For example, data was collected concurrently from different sources (i.e., a cohort of international students, academic, and support staff) to better understand and validate the emerging themes, and thus the accuracy of the findings, of the study (Cresswell 2008; Maree 2007). A qualitative approach was used to generate rich and subjective views on international students' experiences in relation to both language and socio-cultural challenges, and the manner in which these could possibly affect their academic access and success at CPUT. The quantitative approach investigated the proportion of affected international students and how their subjective views of their former schooling experiences had contributed to their English language challenges. A mixed methods approach addressed the issue of representativity and offered researchers the opportunity to '... develop a deep understanding of a phenomenon of interest' through an interpretation of numerical measurements from the student sample population (Henning, Van Rensburg, and Smit 2004; Masue, Swai, and Anasel 2013; Venkatesh, Brown, and Bala 2013). In relation to the qualitative approach, one-to-one in-depth interviews were conducted with lecturers, support staff and students respectively.

\section{Participants}

The participants for the survey included duly registered international students ( $N=32$, see Table 1) from two CPUT campuses ( $\mathrm{N}=15$ from Bellville campus and $\mathrm{N}=17$ from Cape Town campus), randomly selected from all levels of study, in any degree programme and from the six faculties of the university (Business, Engineering, Applied Sciences, Education and Social Sciences, Informatics and Design and Health and Wellness Sciences). These students come from different countries where English might not necessarily be a medium of communication: Angola, Rwanda, Congo, Somali, Sudan, Mozambique, to mention but a few. In addition, nine lecturers from the two CPUT campuses who had 10 months to 33 years' teaching experience, and who were educators of different subjects (namely, graphic design, communication skills, 
language education, computer programming, financial information systems, financial accounting, mechanical and chemical engineering, and dental technology), were invited to participate in the study. Six CPUT support staff with work experience ranging from 2 to 17 years were also invited to take part in the current case study. To ensure that the qualitative data was trustworthy, the above-mentioned participants were selected from different units/departments of the university. In addition, open-ended questionnaires were administered to both undergraduate and postgraduate students from different faculties. In terms of validity and reliability of quantitative data, we ensured that the sample and the content of the questionnaire were representative of the demographics of the international students.

\section{Procedures}

To offer international students the opportunity to express their subjective views about their English language challenges and socio-cultural experiences at CPUT and to ensure that the data collection was carefully triangulated, semi-structured questionnaires were administered by four trained research assistants to 32 randomly selected international students at the Bellville and Cape Town campuses. The group comprised males, females, undergraduate and postgraduate students. The questions were semi-structured and open-ended, and they were framed around the objectives of this study.

Semi-structured and open-ended questions were developed and validated by means of researchers' expertise. One-to-one interviews were conducted to gain insight into academic staff members' perceptions and opinions about the English language challenges experienced by international students. Here, nine lecturers from the faculties of Business, Engineering, Health and Wellness Sciences, Applied Sciences, and Informatics and Design were interviewed. The research concentrated on these faculties because they have the largest enrolments of international students in the institution (CPUT Management Information System (MIS) Statistics)

Additionally, a total of six support staff members from the Office of International Affairs, Library, Centre for Postgraduate Studies and Fundani - Centre for Higher Education Development (Fundani-CHED) were also interviewed. These staff members have day-to-day dealings with international students.

Due to the nature of the study and the size of the participants included in this research, no emphasis was placed on participants' gender, administrative responsibilities or subjects lectured, because the researchers felt these variables would not affect the interviewees' responses. 


\section{Data capturing}

The interviews of between 45 minutes and an hour were conducted by the researchers at a time and site convenient to the interviewees. The duration of interviews allowed the researchers sufficient opportunity to probe further on the interesting and critical issues emerging from the interviewees' responses (Babbie and Mouton 2001; De Vos et al. 2005; Maree 2007). Interviews were audio-recorded by the researchers during the course of the interviews, using RCA VR5320R digital voice recorders. The interviews were subsequently transcribed and saved as Word documents.

\section{Data analysis}

Qualitative data was coded using NVIVO 10 for Windows (QSR International 2012, http://www.qsrinternational.com). NVIVO is a software program designed for the analysis of both structured and unstructured research data to enable researchers to make sense of this data and share their findings effectively. In this regard, the primary investigator of the current research read the content of each interview transcript and made notes, marking important themes for follow-up or further exploration. The data capturer and analyser did the same, so as to confirm the quality of the notes to be used as memos to describe the key themes that emerged from the interviews. The primary investigator and the data capturer / analyser then opened three new folders (for students, support staff and academic staff) with the NVIVO program, where the important broader themes generated were to be saved. The data capturer /analyser then narrowed the themes further and, as such, new, more focused subheadings (referred to as 'nodes') were generated under which the more focused narrow themes were to be stored. These nodes included: Lecturer Profile, Student Profile, Support Staff Profile, English Benefits, Support Awareness, Quality of Language Support, Language Support Monitoring and Evaluation, Recommendations, Language Barriers, Language Challenges, Language Needs, Language Support, Socio-Cultural Adaptation, and Xenophobic Attitudes. These nodes were then stored within the three folders (for students, support staff and academic staff). Statements that referred to each of these generated nodes were then stored as subthemes under these nodes. These statements (subthemes) came from different sources (i.e., different participants, namely: students, support and academic staff).

Researchers then identified overall themes which subsumed subthemes that were categorised under the initial nodes (from different folders), and these were termed 'universal (collective) themes'. For example, if a subtheme, (e.g., 'language challenges') was noted as 
originating from different sources (such as from conversations with a lecturer, a support staff member and a student), that subtheme would appear 3 times as an issue of reference and, as such, it would then assume the status of a 'universal theme', hence 'universal language challenges'. In this regard, NVIVO programme would count it as 3 references coming from 3 different sources. This process was regarded as coding. Table 2 illustrates this procedure:

Table 2: Synopsis of the coding process as extracted from NVIVO file highlighting 'universal (collective) language challenges' theme

\begin{tabular}{|c|c|c|c|c|c|c|c|c|}
\hline WVivo Node & & Sources & References & Datecreated & Creator & Date Edited & Edtitor & \\
\hline SO Uivesa Lanquagn Chalengas & $A$ & 4 & 205 & $201403311252 \mathrm{PM}$ & 2 & $201405911257 \mathrm{PM}$ & 2 & $w$ \\
\hline Dresomic pertonance & 5 & ( & 116 & Do1409\%า $0648 \mathrm{PM}$ & $\mathrm{MK}$ & 201403811257 PM & 2 & \\
\hline O commuicromen chalenges & 3 & & 8 & $20014093150639 \mathrm{PM}$ & MK & 2014033: 1257 PM & 2 & \\
\hline O inpupectolienges & 9 & & 41 & $201400 / 150548 \mathrm{PM}$ & $\mathrm{wx}$ & $201403911259 \mathrm{PM}$ & 2 & \\
\hline 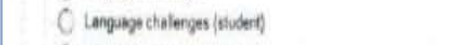 & 31 & 1 & 3 & 20140305 $0536 \mathrm{PH}$ & vK & 201400391 1231 PM & $l$ & \\
\hline O wegage ctallonge (suppert) & 6 & & 30 & 20140323 0355 & NK & 201403311257 PM & 2 & \\
\hline 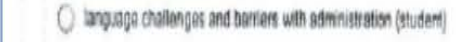 & 18 & 8 & 18 & 20140928 0601 РМ & WK & 201409391 1259 МИ & 2 & \\
\hline
\end{tabular}

For example, Table 2 represents an exemplar universal theme, that is, 'universal (i.e., collective) language challenges'. As an illustration, these 47 sources (i.e., 47 recorded interviews with 9 lecturers, 6 support staff and 32 students) generated 225 references. These references (i.e., 11, $8,41,37,30,18$ ) were grouped under nodes, namely: 'academic performance', 'communication challenges', 'language challenges’ and 'barriers with administration’ respectively.

\section{Ethical clearance}

Participants signed informed consent forms agreeing to participate in this research. In addition, a letter of approval, acceding to the request to conduct the study, was received from the Office of International Affairs. Furthermore, permission to conduct this research was obtained from both the Research and Ethics Committees of Fundani Centre for Higher Education Development at CPUT.

\section{FINDINGS AND DISCUSSION}

This study sought to examine international students' experiences in relation to both language and socio-cultural challenges whilst studying at CPUT, and to ascertain whether these highlighted issues had some bearing on these students' academic access and success. The oneto-one interviews that were conducted with lecturers, support staff and students respectively were meant to provide insight in relation to some of the critical issues that had a direct bearing on the results of the study. From the interviews undertaken, 1137 references were generated 
from 47 sources (32 students, 9 lecturers and 6 support staff). These references were outlined and analysed under 'universal (collective) themes' that were set to address these: students' limitations in English language proficiency; limitations in language support available at the institution; and limitations in students' access to support facilities (previously indicated as LEP, LLS and LAF). These are further outlined in subsequent sections.

Findings revealed various language and socio-cultural issues, highlighting the impact that these issues have on the international students' learning and their access to academic discourse. Most study participants (that is, academic staff, support staff and international students) made an array of negative and positive statements pertaining to the major themes. The rest of the statements suggested the English language proficiency benefits that could be obtained if the students were supported; the quality of necessary language support to be effected was also indicated. Moreover, recommendations regarding monitoring and evaluation of the existing interventions for English language support were made, as well as how awareness programmes regarding this support could be expanded. The cited themes are treated below in the framework of findings of the study.

\section{Universal language challenges}

In this section, all student quotations are cited verbatim, in their original form. Of the total of 1137 references, 18 per cent $(\mathrm{N}=209)$ relate to language challenges that international students reported experiencing. Of the nine lecturers interviewed, five referred to 11 academic performance-related challenges experienced by the international students who were not fluent in English. Three lecturers referred to eight communication challenges, while all nine referred to 41 general challenges that included a combination of difficulties with assignment writing and communication discipline-related tasks, as well as difficulties in communicating with their peers or their lecturers. For example, one lecturer noted:

... we had Chinese, not a single word of English and he sat with a dictionary and translator in class. He received the Rector's medal, there was one subject that he almost failed which was communication skill, on.

Another lecturer brought other perspectives to the issue:

The students struggle to respond in English because they don't have the proper vocabulary but they have the intellectual capacity.

It is mostly the international students from Francophone and Lusophone countries that tend to have problems in their writing and speaking.

English tends to be a third language to them. But they have really improved, when they are in their 
first year they really struggle a lot. But in their third years they communicate much better, especially orally.

Of the six support staff interviewed, all six referred to 30 general challenges experienced by international students, including completing forms, communicating orally, as well as proposal and thesis writing.

Of the 32 international students interviewed, only eight reported that they did not have challenges. The rest $(\mathrm{N}=24)$ reported 37 general challenges (i.e., a combination of difficulties in writing and communicating discipline-related tasks, as well as communicating with their peers or the lecturers). Eighteen of these 37 challenges were linked to communicating with peers, and also communicating with academic and support staff; and 64 references related to academic performance challenges. The following views expressed by the students shed some light on this:

I couldn’t ask questions because I was afraid to embarrass myself as my English was poor. I could not even understand the question in the tests.

I'm not confident about my English but I try to participate, because that's [how] I learn things sometimes and meet new people.

These excerpts from student responses and the statistical data capture the reality of the language challenges that confront international students.

Language challenges in the present study seem to be one of the most critical factors confronting international students - as reported by all the participants - and this reality is, to a great extent, attributed to LEP. Wang et al. reported on the effect of LEP on students in their study, 'As a consequence of this, students were unable to articulate their thoughts and express themselves in written assignments and verbal presentations' (Wang et al. 2008, 147). In the current study, we also found that these language-related challenges are expressed in somewhat similar forms to those reported by Wang et al. (2008), ranging from communication skills difficulties to struggles with academic writing abilities. If international students experience such language competency gaps it stands to reason that their academic performance is bound to be compromised (Beoku-Betts 2004). The inextricable connections between language, language acquisition and cognitively demanding activities (i.e., academic activities), particularly in the case of L2 and L3 users of English in an English-speaking institution such as CPUT, is corroborated by Cummins's (1991; 2008; 2009) notion of CALP. 


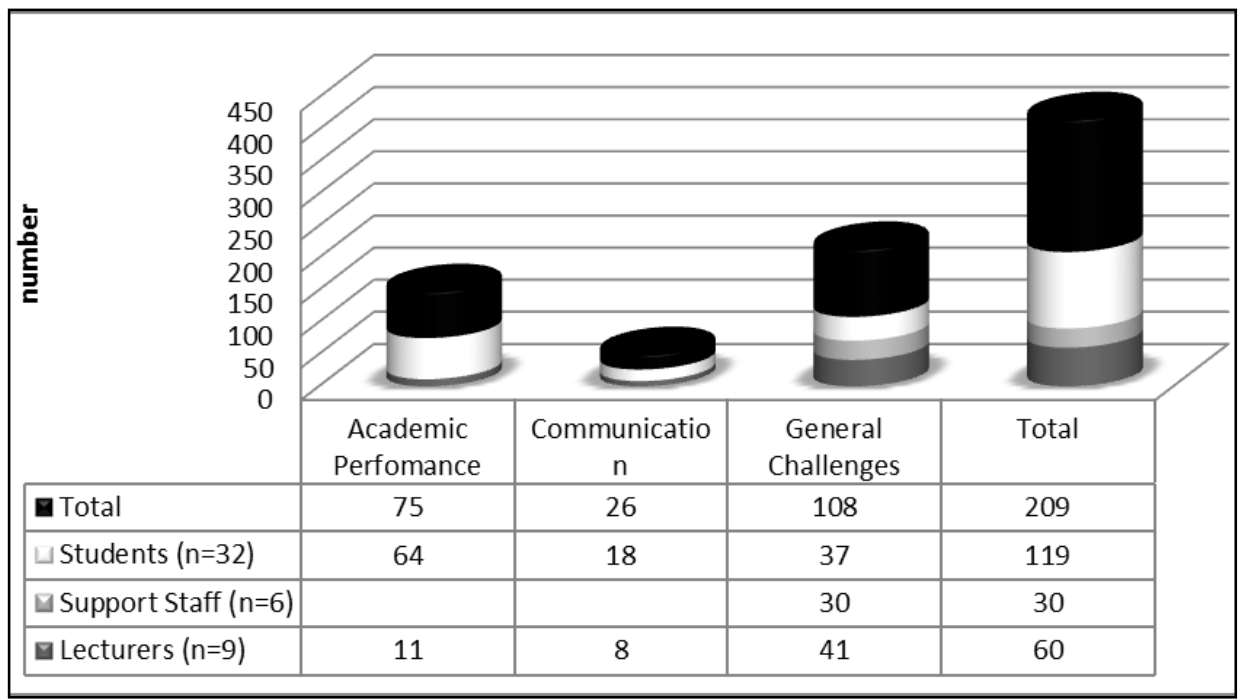

Figure 1: Universal language challenges experienced by international students attending the Bellville and Cape Town CPUT campuses

\section{Universal language barriers}

Out of the 1137 references generated, this section gave rise to 7 per cent $(n=77)$ of these references. Of the six support staff members, two generated four references to barriers experienced by international students with lecturers. The following statement by one support staff member is note-worthy:

They said they were frustrated with the lecturers that sent them, they don't understand the lecturer's accent.

Of the 32 students interviewed, 30 generated references to barriers experienced when communicating with lecturers. The following statement bears testimony to this situation:

We do have that; I mean most of the international students ... the difficulty of the barrier in putting across their communication.

Furthermore, 29 students that were interviewed reported barriers to understanding content in the discipline. The following statements are worthy of note:

... to translate from French to English in my mind. My brain was sored for every single day up to 3 months after school.

The way of speaking of some lecturers I think when they speak it's too fast and then we cannot get what they are saying, accent as well is a challenge sometimes.

Guided by the literature (Wang and Frank 2002) and the results of the present study, it is also evident that language challenges have a negative impact on international students' learning and 
social interaction at CPUT - as noted by most students. For example, issues relating to accent, the speed of a lecturers' speech during lecture presentations, as well as the fact that the students are bound to engage in mental translation from French to English in order to negotiate the meaning of academic concepts, are central and significant language difficulties that international students deal with continuously This latter view, according to Cummins (1991, 75), is true and real in relation to L2 speakers' perception of academic realty: '... transfer of academic skills occurs through the medium of L1 to English L2'.

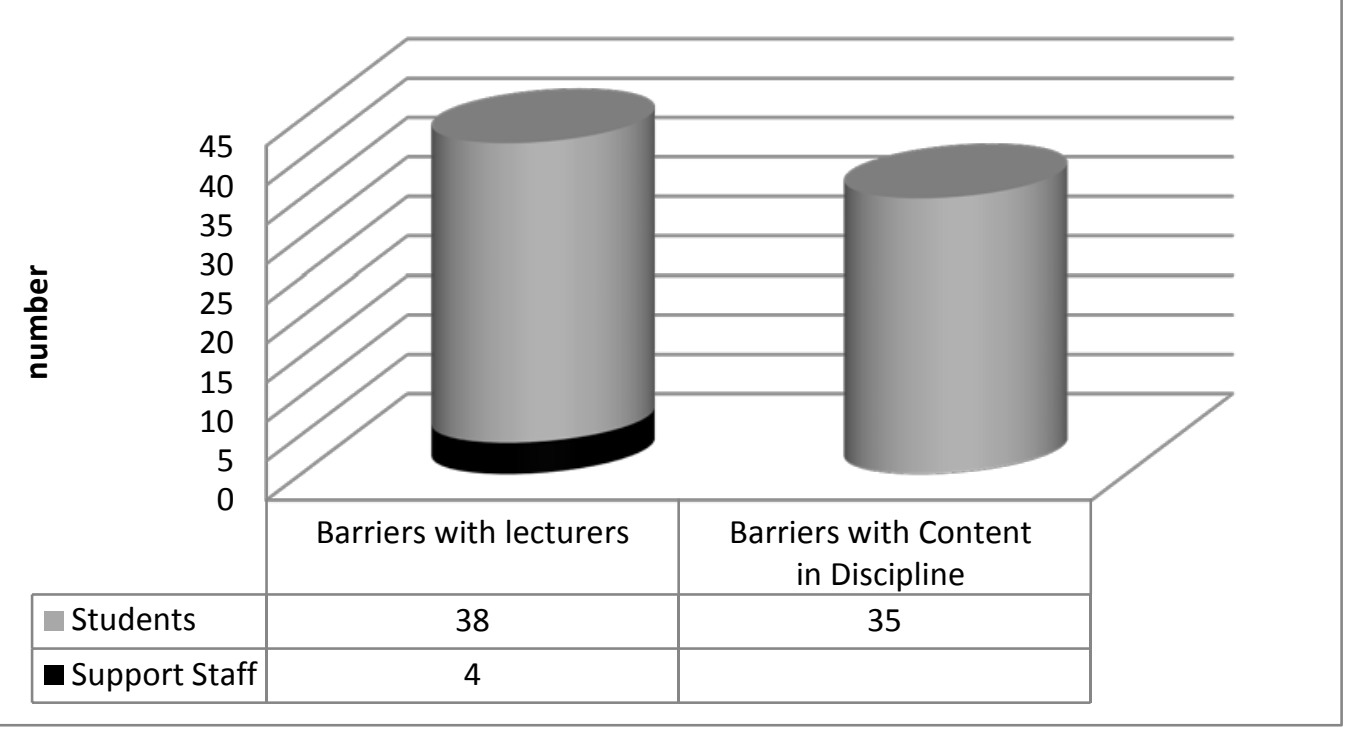

Figure 2: Universal language barriers experienced by international students attending the Bellville and Cape Town CPUT campuses

\section{Universal language needs and support}

Overall, the Universal Language Needs section generated 3 per cent $(n=38)$ references out of the 1137 references These references suggested language experiences as they affected the international students' competence up to general language needs. A total of 36 of these references came from all 32 students, while only two references came from two lecturers. The following statements are worthy of note:

... it was very difficult to understand and speaks English because back at home we are taught English in our own language so that is the disadvantage to us.

My English was bad because in our home country English has just been made an official language and most of the people still speak French like I do. So I am still struggling with English.

It has to be noted that one lecturer referred to 'linguistics background as they affected the international students' competence' and the other one referred to general language needs. More 
importantly, four of the students highlighted that they did not have language needs, while the rest indicated that their 'language experiences affected their competence'.

In this section, 23 per cent $(n=266)$ out of the 1137 were generated, and all related to language support desired. In 168 of these references, suggestions for general language support came from all 32 students. The following statement bears reference to this fact:

We had no language support programmes, if there were any, it would have been a good to building my literacy.

Of the nine lectures, 44 generated references pertained to language support. While six of the lecturers referred to library support, seven lecturers referred to departmental and faculty support. The statements below bear some reference to this:

As far as the language support is concerned, I would advocate the language support that would be open to, because I see a number of things requiring a substantial support in English language. The library has a very generic set of tools to help students in doing their assignment or thesis but those tools are not specific to a particular student need.

Maybe each faculty needs its own writing centre rather than a centralized writing centre that caters for all students.

The other thing I would love them to have is maybe a specific tutor who focuses on them and who has a general understanding of their language, especially at first year level. Also another thing will be more detailed feedback and longer consultation times with them so that we can discuss their challenges.

Six of the support staff made reference to 41 Universal Language Support references:

I think they should recruit consultants from traditional universities who have solid background in writing themselves. Maybe it is also not properly resourced.

It is apparent that most study participants (academic staff, and students) underscored the importance of the language needs, as well as language support, required for international students in order for the latter to gain a certain level of competence, have access to their respective academic discipline and so be in a position to fulfil the requirements of their chosen programmes. Apart from the apparent language needs as a result of LAF, the findings of this study highlight threats that are associated with the lack of, or limited, language support (as reported by both lecturers and students themselves), as this is viewed through CPUT's learning facilities such as the writing centre as well as the library. It stands to reason therefore that if a support mechanism is not fully established by the institution to address the international students' language gap - as echoed by Cummins (2008) - international students will forever 
remain on the receiving end in as far their academic success in concerned. More importantly, the CALP/BICS distinction should play a fundamental role in determining the nature, scope and relevance of a designated support mechanism: 'The significance for policy and practice rests on the fact that educators' failure to take account of the distinction (e.g., in assessment and placement decisions) adversely affects minority students' chances for academic success' (Cummins 1991, 80).

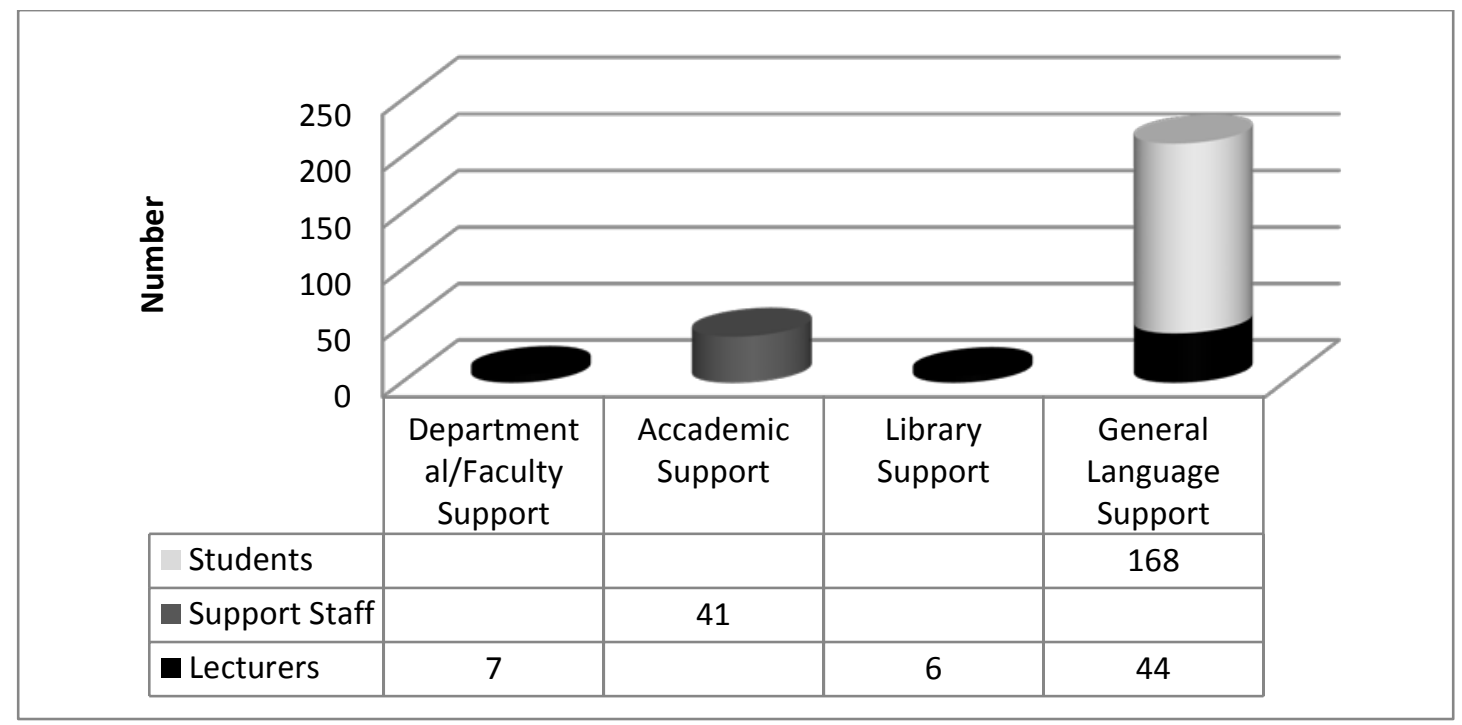

Figure 3: Universal language support, to be implemented to international students attending the Bellville and Cape Town CPUT campuses

\section{Universal socio-cultural difficulties to adapt to at CPUT}

In respect of this section, of the 1137 references, 7 per cent $(n=84)$ related to socio-cultural adaptation. Of the 84 references generated, 74 referred to cultural adaptation, including 27, 16 and 32 emanating from lectures, support staff and students respectively. In the remaining nine references originating from lecturers, social cohesion - as a teaching strategy - was underscored. The following statements relate to this fact:

I don't really see them interacting with other students. They usually sit on their own. And many times when they present their work other students are laughing at their pronunciation. And many times I had to intervene to persuade them to present in front of the classmates who tend to look down upon them just because of their accent.

Last year, I made quite an effort for students to integrate because I was quite worried because it was a monolingual class.

I always allude to a concept called ethnocentrism which is a concept that is part of intercultural communication and which is a form of ignorance when you judge someone based on your own cultural perspective without looking at the person from their perspective; and without understanding the diversity of accents and so on. 
... remind them that the way that people speak is socially constructed.

International students hail from diverse linguistic, cultural and social backgrounds, and it is critical that this enormous diversity is recognised in efforts to address their needs: 'Any discussion of the challenges facing international students needs to take account of the heterogeneity of the international student population' (Ryan and Viete 2009, 303). For example, the following excerpts from the data further exemplify how a lack of English proficiency affects international students’ ability to socialise with local students:

I am always struggling. I can’t express myself well. Even though when we are asked to work in groups, I tend be rejected. People talk in their vernacular language and this has affected me negatively ... (Student response)

There is little or no interaction with other groups like local students. Their interaction is limited to members of their own foreign group ... this is partly because of language but also culture and general affinity with what is familiar to you and you can easily trust .... (Lecturer response)

From these quotes, language is constructed as a prism through which international students mediate their relationship with local students. As migrants living far away from home, they yearn for acceptance but their ability to adapt and integrate is not only impeded by their limited English proficiency but cross-cultural communication difficulties further exacerbate the problem, as it underlies everything in Hall and Halls' (1990) terms.

We have also found that international students in the present study are confronted by feelings of social isolation and alienation and, as such, find it impossible to adjust culturally in an unfriendly environment. This reality is largely influenced by, among other things, lack of integration and social cohesion which are reflected in the current teaching and learning practices. Arguably, the context, along with the system in which international students find themselves, operates by a different set of socio-cultural rules, and is thus not compliant with their cultural idiosyncrasies. This, according to Hall and Hall (1990, 4), is what contributes to a system failure, and this can be attributed to i) unconscious application of 'one's own rules to another system', and ii) deliberate rejection of rules when one is 'trying to force one's own rules on another system'. In the context of the current study, it is also apparent that international students' learning environment is entangled in the subtle conditions of power relations. This situation does not only threaten this segment of the student population and prevent them from becoming fully fledged participants in a learning community, but it carries potential for misinterpretations and misunderstandings in their designated learning space.

Some of the views regarding language and the manner in which culture relates to it (at 
least for the students) confirm that effective cross-cultural (intercultural) communication on the CPUT campuses remains a myth rather than a reality. In support of this view, Ryan and Viete (2009, 305), brings in a crucial perspective when arguing that, '... the sophistication of a student's language may be equated with ability ... but may not be a good indicator of what the student has learnt, particularly if the cultural knowledge and experiences are rarely shared'. In a nutshell, although CPUT international students experience socio-cultural challenges, separate from their language difficulties, there is also an undeniable relationship between their language inadequacies and their socio-cultural challenges. For them, the ability to speak English fluently plays a critical role in their process of socio-cultural adjustment and adaptation to studying and living in South Africa (Swami et al. 2010).

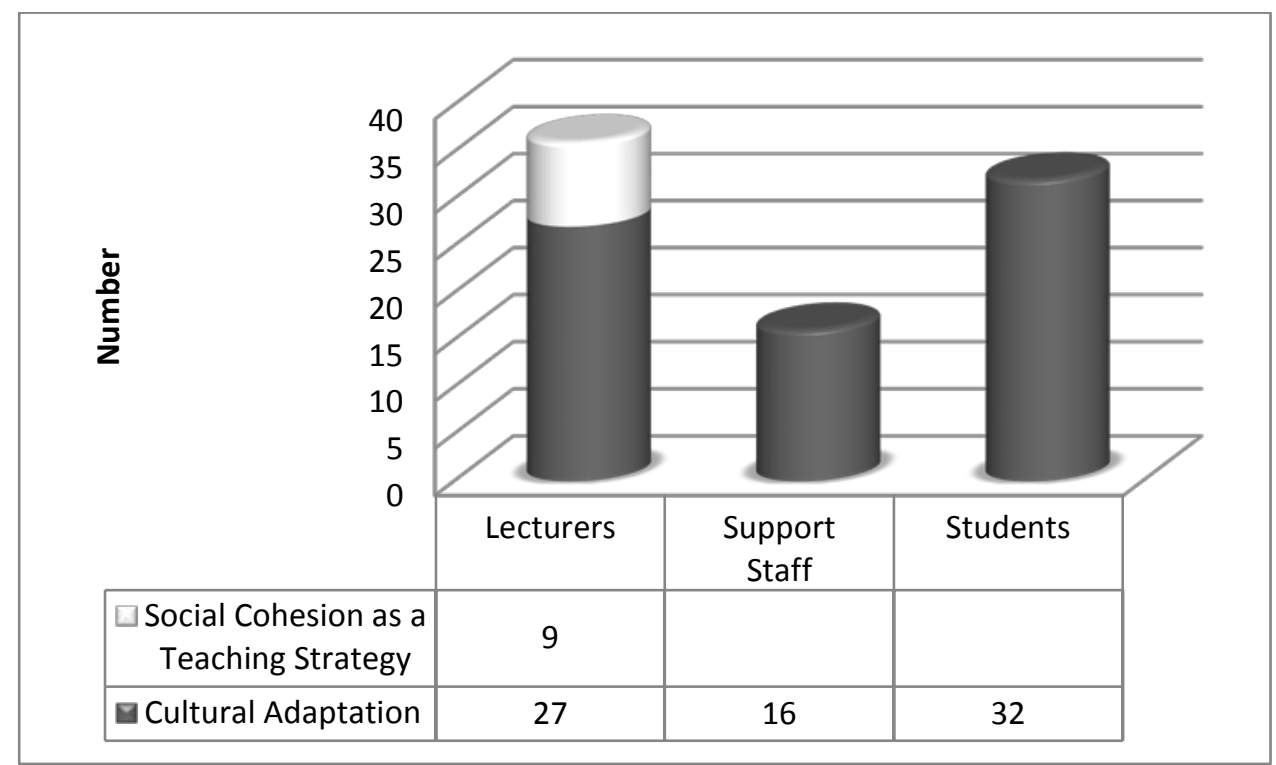

Figure 4: Socio-Cultural adaptation experienced by international students attending the Bellville and Cape Town CPUT campuses

\section{CONCLUSION AND RECOMMENDATIONS}

It is apparent that perceptions of reality are mediated through language; and if our command of a particular language is poor or weak, it stands to reason that our ability to comprehend 'academically demanding activities' will be characterised by conceptual and terminological limitations (Ralarala et al. in press, 2017). For international students - as has been shown in this study - the undeniable relationship between language inadequacies (with specific reference to LEP, LAF and LLS) and academic performance has far-reaching implications for access and success in higher education. For example, apart from economic constraints, resulting from international students being far from home and inevitable extended enrolment in a single programme, academic exclusion owing to underachievement or poor academic performance 
could be an unbearable consequence. Furthermore, salient links between international students' English language inadequacies and their socio-cultural challenges have proven to have a negative impact, and have contributed to a certain level of discordance when these students have to relate to fellow students and lecturers in a learning context such as CPUT. As a result of this, feelings of despondency and nostalgia are quite rife among the majority of international students who participated in the study.

As lecturers and support staffs have equally expressed concerns over the language as well as socio-cultural challenges faced by international students, and the negative impact that these have on their academic performance and social interactions, the matter warrants serious consideration by the institution that admits these students. If the situation remains unattended, it becomes tantamount to an indictment upon the institution. The establishment of viable and enabling mechanisms that constitute language and cultural support are worthy of consideration:

- To respond to the issue of adequate language support, a tailor-made admission test, which should serve as a diagnostic tool sufficient to determine the various needs and levels of required English language support, is required as early as registration. The spin-offs attached to this initiative could extend beyond resolving the plight of international students and benefit local students, as the present study has revealed that this segment of the student population is equally at risk in as far as language challenges in relation to academic success are concerned.

- The linguistic and cultural profile of international students does not seem to be an important factor to those (mainly academic and support stuff) who deal with them continuously. Yet, recognition of such elements in the context of diversity, particularly by academic staff in the course of their teaching practices, could, positively, mean acceptance and boosting of their self-esteem rather than their experience of rejection and exclusion, as has been indicated in this study. The more that is known about them and their background the better. In fact, the more integration is reinforced in a diverse learning space, the better the chances are of students and academic staff developing awareness of, and dealing with, subtle cultural differences that could have adverse effects. This should address the issues of social exclusivity and cultural integration, both of which emerged powerfully in the findings

- $\quad$ The need to capacitate both support staff and academic staff, especially those that are in daily contact with current and new international students, cannot be overemphasised. Such work would occur through programmes that are foregrounded in the domain of 
intercultural communication. By so doing, these staff members should be able to identify and constructively address the language and socio-cultural challenges of this cohort of students.

Of course, these developmental initiatives are bound to have huge financial and human resource implications for the institution. However, the return on investment is justified, considering the potential this could have on higher achievement and social cohesion, both of which are linked to institutional strategic goals.

Apart from instigating an institutional dialogue, this study should be perceived as a 'springboard' that could inform further studies in this direction. In fact, the findings of the current research further magnify a strong need to conduct audits of the CPUT register - through a longitudinal study - in an effort to present a reliable prediction of the association between English language inadequacy and academic performance of those international students who experience language-related challenges associated with communication and academic writing difficulties disabilities. This will corroborate Beoku-Betts' (2004) argument that, if international students experience gaps of knowledge, their academic performance will be compromised.

\section{ACKNOWLEDGEMENTS}

We would like to pay tribute to the participants who made this research possible. They comprise CPUT academic staff, support staff and international students. We are also grateful to the university's structures such as the Language Working Group and the Senate Language Committee that saw the need for this investigation. Also, we are indebted to Fundani Centre for Higher Education Development for funding the initial project - of which this is an offshoot. Top of the list is our research assistants who coped with some of the interviews and transcriptions.

\section{REFERENCES}

Abriam-Yago, K., M. Yoder and M. Kataoka-Yahiro. 1999. The Cummins Model: A framework for teaching nursing students for whom English is a second language. Journal of Transcultural Nursing 10(2): 143-149.

Adler, R. and G. Rodman. 2006. Understanding human communication. Oxford: Oxford University Press. http://www.abebooks.co.uk/book-search/title/understanding-human-communication/ author/adler-rodman/ (accessed 28 April 2015).

Barratt, M. F. and M. E. Huba. 1994. Factors related to international undergraduate student adjustment in an American Community. College Student Journal 28(4): 422-436.

Bartram, B. 2008. Supporting international students in higher education: Constructions, cultures and 
clashes. Teaching in Higher Education 13(6): 657-668.

Babbie, E. and Mouton, J. 2001. The practice of social research. 9th ed. Belmont: Wadsworth. http://www.worldcat.org/title/practice-of-social-research/oclc/44076041 (accessed 28 April 2015).

Beoku-Betts, J. 2004. African women pursuing graduate studies in the sciences: Racism, gender bias and Third World marginality. NWSA Journal 16(1): 116-135.

Cape Peninsula University of Technology. 2014. Management Information System (MIS).

Constantine, M. G., M. Kindaichi, S. Okazaki, K. A. Gainor and A. L. Baden. 2005. A qualitative investigation of the cultural adjustment experiences of Asian international college women. Cultural Diversity and Ethnic Minority Psychology 11(2): 162-175.

CPUT see Cape Peninsula University of Technology.

Creswell, J. W. 2008. Educational research: Planning, conducting, and evaluating quantitative and qualitative approaches to research. $2^{\text {nd }}$ ed. Upper Saddle River, NJ: Merrill/Pearson Education.

Cummins, J. 1991. Conversational and academic language proficiency in bilingual contexts. In Reading in two languages: Aila Review-Revue De Laila, ed. J. Hulstijn and J. Matter. Amsterdam: Haveka B.V.

Cummins, J. 2008. BICS AND CALP: Empirical and theoretical status of the distinction. In Encyclopedia of Language and Education, ed. B. Street and N. Hornberger. 2nd ed. New York, NY: Spring Science.

Cummins, J. 2009. Basic interpersonal communicative skill and cognitive academic language proficiency. http//www.iteachilearn.org/cummins/bicscalp.html (accessed 23 August 2014).

De Vos, A. S., H. Strydom, C. B. Fouche and C. S. L. Delport. 2005. Research at grass roots for the social sciences and human service professions. 3rd ed. Pretoria: Van Schaik.

Guo, S. and M. Chase. 2011. Internationalisation of higher education: Integrating international students into Canadian academic environment. Teaching in Higher Education 16(3): 305-318.

Hall, E. T. and M. R. Hall. 1990. Hidden differences: Doing business with Japanese. London: Anchor Books.

Henning, E., W. van Rensburg and B. Smit. 2004. Finding your way in qualitative research. Pretoria: Van Schaik.

Karuppan, C. M. and M. Barari. 2011. Perceived discrimination and international students' learning: An empirical investigation. Journal of Higher Education Policy and Management 33(1): 67-83.

Kim, H. Y. 2011. International graduate students' difficulties: Graduate classes as a community of practices. Teaching in Higher Education 16(3): 281-292.

Lee, J. J. and C. Rice. 2007. Welcome to America? International student perceptions of discrimination. Higher Education 53(3): 381-409.

Maree, K., ed. 2007. First steps in research. Pretoria: Van Schaik.

Masue, O. S., I. L. Swai and M. G. Anasel. 2013. The qualitative-quantitative 'disparities' in social science research: What does qualitative comparative analysis (QCA) brings in to bridge the gap? Asian Social Science 9(10): 211-221.

McLellan, C. E. 2009. Cooperative policies and international students: Do policy spirits match experiences? Higher Education Policy 22(3): 283-302.

QSR International. 2012. NVIVO 10 for Windows. http://www.qsrinternational.com (accessed 21 October 2013).

Pineteh, E. and M. K. Ralarala. 2013. Research report on the language challenges experienced by international students at Cape Peninsula University of Technology. Unpublished Research Report. Cape Peninsula University of Technology.

Poyrazli, S. and P. R. Kavanaugh. 2006. Marital status, ethnicity, academic achievement, and adjustment strains: The case of graduate international students. College Student Journal 40(4): 767-780. 
Rabatsoa, J. and R. Singh. 2012. Challenges experienced by history learners during assessment using the medium of English. South African Journal of Higher Education 26(1): 10-23.

Ralarala, M. K., E. Ivala, K. Barris, N. Leach, L. Manashe and Z. Somlata. (In press). 2017. Reflections on language development and multilingualism in Higher Education: A case for the Cape Peninsula University of Technology. In Multilingualism and Intercultural Communication: A South African Perspective, ed. R. H. Kaschula, P. Maseko and H. E. Wolff. Johannesburg, Wits University Press.

Ramburuth, P. and J. McCormick. 2001. Learning diversity in higher education: A comparative study of Asian international and Australian Students. Higher Education 42(3): 333-350.

Ryan, J. and R. Viete. 2009. Respectful interactions: Learning with international students in the Englishspeaking academy. Teaching in Higher education 14(14): 303-314.

Sheridan, V. 2011. A holistic approach to international students, institutional habitus and academic literacies in an Irish third level institution. High Educ 62: 129-140.

Sherry, M., P. Thomas and W. H. Chui. 2010. International students: A vulnerable student population. Higher Education 60: 33-46.

Swami, V., A. Arteche, T. Chamorro-Premuzic and A. Furnham. 2010. Sociocultural adjustment among sojourning Malaysian students in Britain: A replication and path analytic extension. Social Psychiatry and Psychiatric Epidemiology 45: 57-65.

Venkatesh, V., S. A. Brown and H. Bala. 2013. Bridging the qualitative-quantitative divide: Guidelines for conducting mixed methods research in information systems. MIS Quarterly 37(1): 21-54.

Wang, C. W., C. Singh, B. Bird and G. Ives. 2008. The learning experiences of Taiwanese nursing students in Australia. Journal of Transcultural Nursing 19(2): 140-150.

Wang, J. and D. Frank. 2002. Cross-cultural communication: Implications for effective information services in academic libraries. Portal: Libraries and the Academy 2(2): 207-216.

Yeh, C. J. and M. Inose. 2003. International students' reported English fluency, social support satisfaction, and social connectedness as predictors of acculturative stress. Counselling Psychology Quarterly 16(1): 15-28. 